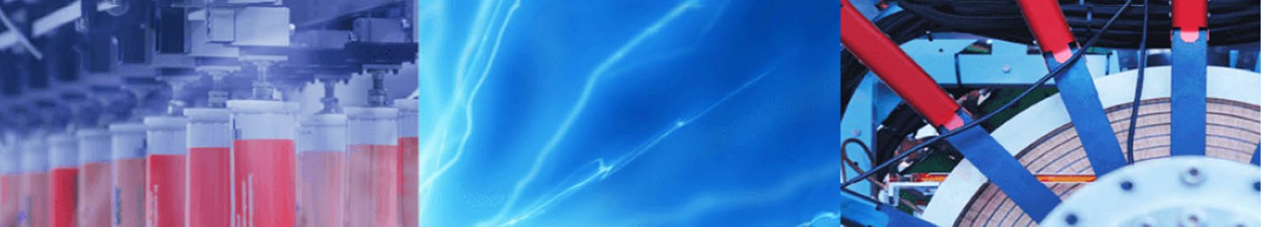

Research Article

\title{
Manufacturing process design of high-pressure graphite-blasting for mechanical production of turbostratic graphene
}

\author{
Kamilia Aokal $^{1} \cdot$ Abdul Hai Alami $^{2}$ D $\cdot$ Ali Cheaitou $^{3} \cdot$ Mohammad Ali Abdelkareem $^{1,2,4}$
}

Received: 26 December 2020 / Accepted: 18 March 2021 / Published online: 31 March 2021

(C) The Author(s) 2021 OPEN

\begin{abstract}
In this paper a manufacturing process is introduced to treat the bulk surfaces of surfaces via graphite powder blasting to directly produce an adherent layer of graphene. Subsequently, the study aims to correlate optical, thermal and electrochemical modifications with treatment parameters such as blasting pressure, nozzle distance and number of passes. After the treatment, the target surface has enhanced spectral, thermal and electrochemical properties because of the graphene's turbostratic nature to adhesion to its surface. The thermal stability performance showed a consistent $5 \%$ increase relative to a bare aluminum substrate. A two-fold increase in corrosion resistance is seen in the sample compared to bare aluminum while diffuse absorbance values enhancement is around three-fold. This proposed manufacturing method provides straightforward and effective treatment at various degrees of automation. Since the deposited graphene substrate can cover a large area, it can be applied as a final layer on thermal collectors, PV panels and for other applications. It is possible to adopt this process to other well-established treatment plants without requiring high investments in the overhead expenses.
\end{abstract}

Keywords Turbostratic graphene · Bulk deposition · Mechanical deposition · Graphite-blasting

\section{Introduction}

Surface modification is an important aspect of various applications, especially in energy conversion and storage, catalytic and corrosion control applications [1]. This modification can take place via various processes be it electrochemically, chemically, thermally and mechanically among others [2]. Finding a facile method to incorporate surface modification is almost as important as the selection of the coating itself. Ideally, the selected process should be facile, amenable to automation, safe and effective. Otherwise it would create unforeseeable technical and economic complications.

Graphene is a two-dimensional material that has exceptional chemical and physical properties and has enjoyed many applications in applications of energy conversion [3]. Turbostratic graphene, the result of structure misorientation, constitutes of multiple-layer graphene with rotational stacking (or through-plane) disorder [4]. A twisted structure of the multi-layered graphene is a resultant of a rotational angle of the in-plane carbon sheet and is seen to produce astounding effects such as superconducting and insulating properties $[5$, 6]. Quite notably, thermal properties of turbostratic graphene are much lower than that of single layer graphene. Simulation results conducted by Nie et al. show in-plane thermal conductivities of $100 \mathrm{~W} \cdot(\mathrm{m} \cdot \mathrm{K})^{-1}$ to around $650 \mathrm{~W} \cdot(\mathrm{m} \cdot \mathrm{K})^{-1}$ across different layer $(>2)$ configurations and temperature variants while interfacial thermal conductivity is seen to significantly decrease to

$\triangle$ Abdul Hai Alami, aalalami@sharjah.ac.ae| ${ }^{1}$ Centre for Advanced Materials Research, University of Sharjah, Sharjah, United Arab Emirates. ${ }^{2}$ Sustainable and Renewable Energy Engineering Department, University of Sharjah, Sharjah,

United Arab Emirates. ${ }^{3}$ Department of Industrial Engineering and Engineering Management Sustainable Engineering Asset Research Group, University of Sharjah, Sharjah, United Arab Emirates. ${ }^{4}$ Chemical Engineering Department, Minia University, Elminia, Egypt. 
values less than that of $0.5 W \cdot(m \cdot K)^{-1}$. This is mainly due to the mismatch suffered by the stacked structure as phonon barriers are introduced. The thermal properties of turbostratic graphene can be described using the anisotropic ratio, $\eta$, that is the ratio of in-plane to through-plane thermal conductivity [7]. The reduction of the conductivity out-of-plane gives rise to a higher anistropic ratio and for the randomly stacked turbostratic structure of graphitic materials, the thermal conductivity decreases significantly [8]. Therefore, increased thermal anisotropy ratio values in low dimensional materials compared to pristine graphene make it favorable to be used for tunable thermal management in the electronics industry on a nanoscale level by the careful alteration of the rotational angles of the $\mathrm{sp}^{2}$-carbon planes [9-11].

Twisted graphene have been synthesized chemically by chemical vapor deposition (CVD) or grown epitaxially on silicon carbide $(\mathrm{SiC})$ substrates by thermal decomposition $[12,13]$. Mechanical exfoliation technology, such as micromechanical cleavage is also attempted experimentally to produce the rotated structure $[14,15]$. The experimental results, however, rely on the analysis of random folded sheets of graphene with other forms of graphene present.

A technique for mechanical exfoliation with increased, on the other hand, using a centrifugal milling with highenergy was already mentioned in papers [16] in which to initially start the process of mechanically synthesizing and depositing multiple layers of turbostratic graphene a highly pure graphite is required in the ball-free ball milling process. The forces applied to the graphite powder will be utilized to mechanically shear the particles which will result in exfoliating the copper liner's exterior.

Mechanical exfoliation techniques are well known to be plausible for large scale applications, especially when these processes are used on a wide scale for other purposes.

The process of graphite air blasting [17], for example, has originated from the sand blasting process which is used mainly used for large-scale cleaning of structures. For softer material, such as graphite, the process causes the graphite powder to adhere to the target surface, similar to paintball shots. Some parameters have to be adjusted, such as the operational pressure, distance from nozzle to target, number of passes as well as surface roughness [18].

As an easily scalable process, the blasting mechanism has been proposed in this study for turbostratic graphene synthesis and deposition on bare aluminum substrates with the aim of enhancing performance of certain applications so the produced sheets will be tested in terms of thermal, optical and corrosion behavior.

In this work we investigate the aforementioned deposition process in terms of parameters leading to the successful deposition of graphene on metallic substrates. First, the process is described in terms of the equipment and materials, followed by the characterization of resulting graphene material. Then, the thermal, electrochemical and optical properties of the parts produced by this process are evaluated via specifically designed experiments. Finally, an enclosure design is proposed to host this process to trap and dispose of suspended graphite powder in the air, which could be dangerous to health if left uncollected. The economic feasibility of such structure and pertinent components needed are also outlined and discussed. The attractive feature for such a process is the speed, ease of use and wide applicability for energy conversion and storage devices, particularly to facilitate the production of graphene film, graphene aerogels and graphene ink.

\section{Experimental}

\subsection{Material and equipment}

The particle size of the graphite powder ranges between 63-125 $\mu \mathrm{m}$ which can be extracted from fine industrial graphite. This is to avoid clogging a $1.6 \mathrm{~cm}$ nozzle-diameter and be easily carried on air jet orifice of about $0.476 \mathrm{~cm}$ to allow an uninterrupted graphite stream for blasting as any particle with bigger size will be restricted from passing. $1 \mathrm{~mm}$ thick sheets of aluminium $(10 \mathrm{~cm} \times 10 \mathrm{~cm})$ is used as substrates and ground with 120 grit sandpaper to unify surface conditions. Distilled water was used to wash the samples, then the samples were fixed in front of the blasting nozzle. The sand blasting gun has a reservoir of $500 \mathrm{ml}$ containing graphite powder and used simultaneously with an air compressor of high pressure. The exterior of the sample and the sand blasting gun should be placed with $20 \mathrm{~cm}$ in-between as a minimal distance so as to preserve the aluminium surface and to place emphasis purely on the sheer deposition of the graphitic material.

\subsubsection{Deposition system design}

Figure 1 shows a CNC machine (3D Carbide) that is being utilized to monitor the depositing process, this can be achieved by maintaining the vertical position of the nozzle and precisely positioning it along the horizontal axis and the $Z$-axis.

The deposition rate was set as one pass, then two passes, then three passes this was achieved by programming the CNC machine to move forward and backward horizontally. Through the whole experiment the machine's velocity was set at $0.1 \mathrm{~m} / \mathrm{s}$, and the compressor's pressure 
Fig. 1 a schematic of the deposition process, $\mathbf{b}$ side outlook and $\mathbf{c}$ a top outlook of the graphite blasting setup by using a CNC machine and a pressure nozzle

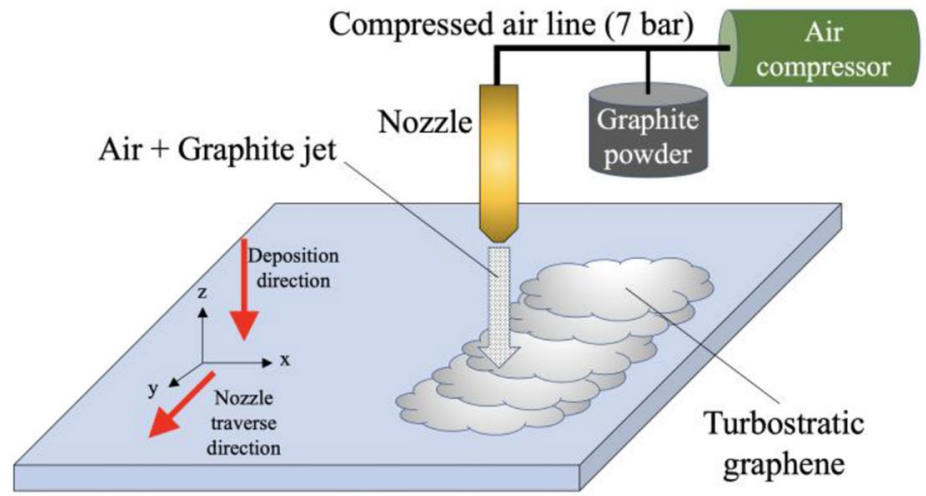

(a)

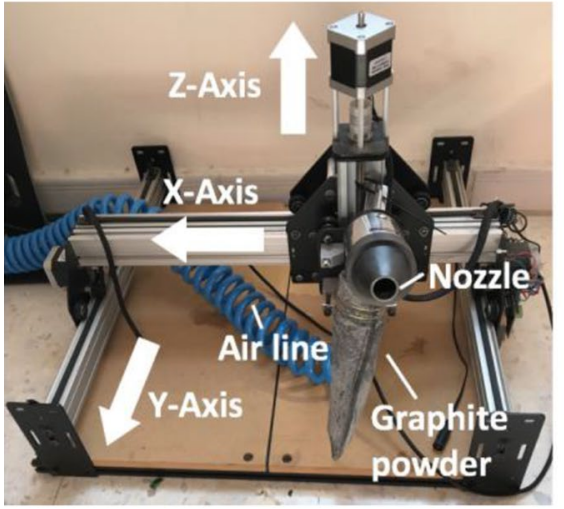

(b)

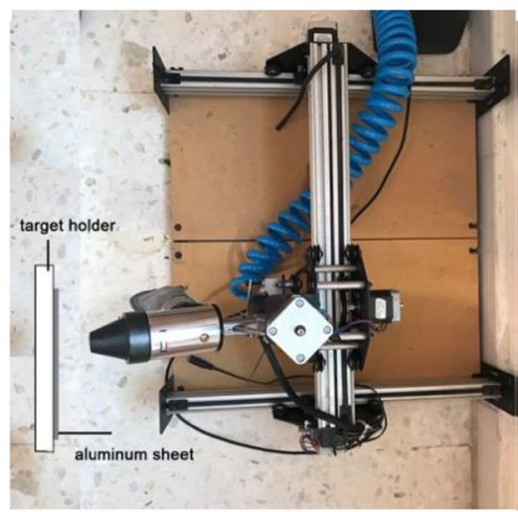

(c) was fixed at 8 bar as the acting force for potential physical adherence to the substrate.

The obtained metallic substrates were used for further testing and characterization after sonicating in ethanol for $10 \mathrm{~min}$ for the removal of excess deposits. The nozzle size and air jet orifice of the siphon blaster were fixed at $1.6 \mathrm{~cm}$ and 8 bar respectively.

To consider graphite's quantity, as well as the time it would take to fully coat a commercial 1 by $2 \mathrm{~m}^{2}$ substrate, a known amount the graphite powder was released and the time for full expulsion was recorded.

\subsection{Material characterization and testing}

To ensure that the deposited carbon material is turbostratic graphene, micro Raman spectroscopy is utilized to detect the typical peaks of graphene displayed as the $D, G$ and $2 D$ peaks that correspond to $~ 1350, \sim 1580$ and $\sim 2700 \mathrm{~cm}^{-1}$ respectively. Random locations were scanned with $10-50 \%$ laser intensity where the illuminated area on the sample is approximately $1 \mu \mathrm{m}$. Normalizing and scanning (an area of $200 \mu \mathrm{m}^{2}$, looking if the G-band areas are bigger than $1581.6 \mathrm{~cm}^{-1}$ ) the spectral dataset provided the potential for better analyzing the covering deposition on the aluminum substrates.
Spectral analysis measuring diffuse reflectance was performed in the ultra-violet and visible (UV-Vis) region and the visible and near-infrared (Vis-NIR) region using two separate spectrometers, with wavelengths expanding from 200 to $815 \mathrm{~nm}$ within an integrating sphere. The integrating sphere from OceanOptics has a sample aperture of $1.016 \mathrm{~cm}$ diameter and a built-in tungsten halogen light source (LS-1-LL) that is attached to the two Maya-2000-Pro high-resolution spectrometers from OceanOptics. The spectrometers have a resolution of $0.2 \mathrm{~nm}$ and 300 lines per $\mathrm{mm}$ diffraction gratings and $10 \mu \mathrm{m}$ entrance slit. To compare between several turbostratic graphene depositions bare aluminium is employed as the reference surface with the ability to capture $100 \%$ reflectance.

To test the thermal stability a k-type thermocouples with circular diameter of $0.1 \mathrm{~mm}$ of a $750 \mathrm{~W}$ heating plate is required, the test was performed on an area of $1 \mathrm{~cm}^{2}$. The k-type thermocouple acquires precise readings, consequently achieving high responsivity to any variations in temperature. The nature of the heating induced fluctuating effects with the aid of a built-in thermostat in the heating plate. This provided an insight on the thermal stability of the samples after continuous cycles of heating and cooling. 
The corrosion rate of the turbostratic graphene-coated samples is calculated to obtain an idea about the effect of the protection provided to the turbostratic graphene deposition against corrosion on the metal's exterior in normal environmental conditions. Experimental tests were conducted in $\mathrm{NaCl}$ of $0.1 \mathrm{M}$ and Tafel analysis obtained all the required results. The VSP-300 potentiostat performed the electrochemical tests, acquired from Bio-Logic, where resolution is about $30 \mu \mathrm{m}$. A linear sweep was utilized to perform the required tests, the linear sweep scanned at a rate of $0.5 \mathrm{mV} / \mathrm{s}$, and the sweep extended between $-1 \mathrm{~V}$ cathodic potential and $+1 \mathrm{~V}$ anodic potential in comparison to an open-circuit voltage. Tafel extrapolation, found on the EC-lab software, was utilized to find the corrosion rates. Field emission scanning electron microscopy was carried out for all three deposition passes (one, two and three passes). The accelerating voltage for all measurements was set at $1 \mathrm{kV}$ with the Apreo $C$ field emission (FE-SEM) from Thermoscientific (Thermo Fisher Scientific, Brno, Czech Republic) operating at low vacuum with an electrostatic lens.

\section{Results and discussion}

\subsection{System framework}

\subsubsection{Amount of graphite needed for full coverage on aluminium substrate}

Taking into account the atmospheric pressure, the test pressure and the tank size, it is possible to calculate the amount of air in the tank and subsequently- with the addition of the time for deposition, the volumetric flow rate of the blasting gun.

$$
\begin{aligned}
\text { Air in the tank } & =\frac{\text { Tank size } \times \text { Test Pressure }}{\text { Atmospheric Pressure }} \\
& =\frac{0.05\left(\mathrm{~m}^{3}\right) \times 8(\text { bar })}{1(\text { bar })}=0.4 \mathrm{~m}^{3}
\end{aligned}
$$

$$
\begin{aligned}
\text { Volumetric flowrate } & =\frac{\text { Air in Tank }}{\text { Time till air drains out }} \\
& =\frac{0.4\left(\mathrm{~m}^{3}\right)}{5.1197(\mathrm{~min})}=0.077 \mathrm{~m}^{3} / \mathrm{min}
\end{aligned}
$$

Given the graphite density to be $2260 \mathrm{~kg} / \mathrm{m}^{3}$, the flow rate of mass is calculated and was found as $176.28 \mathrm{~kg} / \mathrm{min}$. With that, the composition of graphitic content is approximated by experimentally evaluating the mass of graphite in the blasting gun before and after the discharging process, which was found to equal $0.0656 \mathrm{~kg} / \mathrm{min}$. It surfaced that the graphite's percentage in the fluid flow was about $0.04 \%$ which is about $0.0705 \mathrm{~kg} / \mathrm{min}$. For good homogeneity, it is estimated that $4.5 \mathrm{~kg}$ of powdered graphite is needed to cover a 1 by $2 \mathrm{~m}^{2}$ substrate where the deposition occurs in $62.5 \mathrm{~min}$. At most, and for commercial applications, a continuous 8-h air supply is needed for the whole process.

\subsection{Substrate characterization and performance}

Raman spectroscopy results, shown in Fig. 2, were achieved at $514 \mathrm{~nm}$ laser power to confirm turbostratic graphene deposition.

The single-pass $\left(\mathrm{S}_{1}\right)$ sample (Fig. 2) lacks a visible defect peak $\left(\sim 1350 \mathrm{~cm}^{-1}\right)$. This could be attributed to the impact of energy produced at the exterior of the substrate by the particles of graphite, which results in mechanically exfoliating the powdered graphite and turning it into platelets of turbostratic graphene. Such turbostratic deposition is generally characterized by the vertical line of symmetry of the 2D peak at Raman shifts of $\sim 2700 \mathrm{~cm}^{-1}$ and a line width of $70 \mathrm{~cm}^{-1}$ [19].

The mapped Raman images in Fig. 3 portray the distribution of the turbostratic graphene deposition. Here, a straightforward indication to detect the success rate of deposition is used, if the variation of wavelengths is much more than that of the of the G-band of graphite, which is about $1581.6 \mathrm{~cm}^{-1}$, the deposition of the turbostratic graphene will successfully take place.

Figure 4 shows the distribution of the trend extracted from the mapping data presented in Fig. 3, which features the three-pass sample. It is noted that a skewed coverage at lighter coloration and this area indicates a better

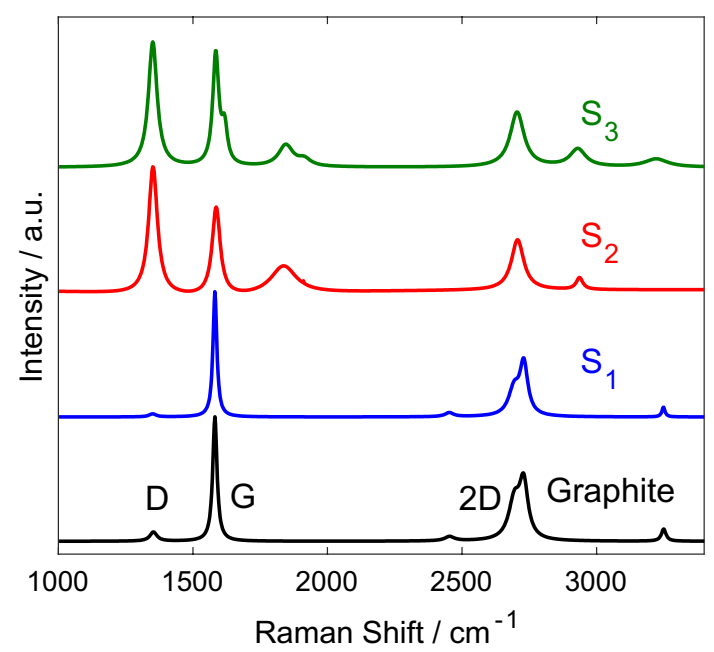

Fig. 2 The single $\left(\mathrm{S}_{1}\right)$, two pass $\left(\mathrm{S}_{2}\right)$, and three pass $\left(\mathrm{S}_{3}\right)$ Raman spectra in comparison to graphite 
Fig. 3 Raman mapped depictions of the single (S1), second pass (S2), and third pass (S3) samples to cover G-band positions

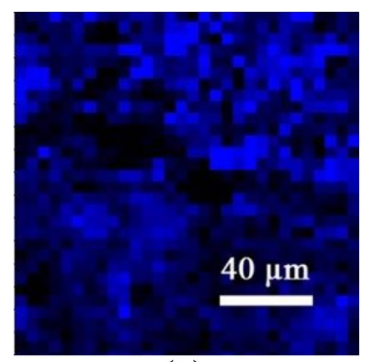

(a)

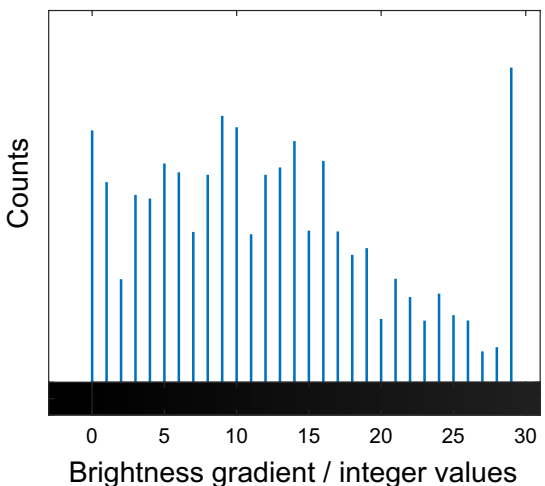

(b)

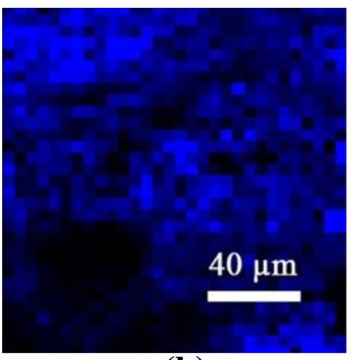

(b)

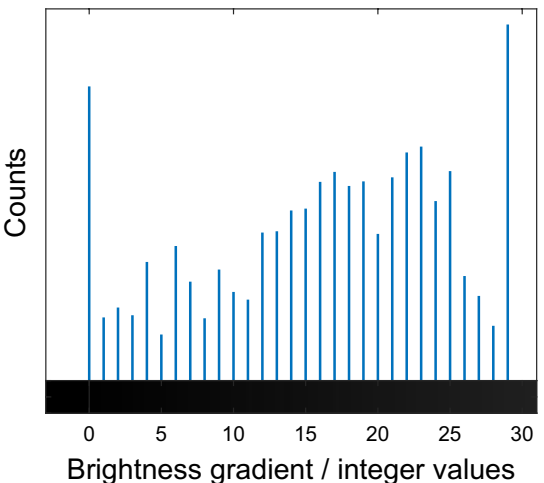

(c)

Fig. 4 Spectral histograms of the single (S1), second pass (S2), and third pass (S3) samples to cover G-band positions

turbostratic graphene deposition. $\mathrm{S}_{1}$ and $\mathrm{S}_{2}$ show positive skewness whereas $S_{3}$ shows negative skewness. This indicates a higher mean value of brightness is expected in the three-pass sample. And as expected, the mean is highest in the three-pass sample with a value of 15.9 with a standard deviation of 0.090, as compared to the single and two-pass samples that have average values of 10.76 and 12.67 and standard deviation values of 0.097 and 0.091 , respectively.

\subsection{Microstructural analysis}

Field emission scanning electron microscopy was carried out for all three deposition passes (one, two and three passes). The accelerating voltage for all measurements was set at $1 \mathrm{kV}$ in the SEM machine. The results for the reference specimen and for one, two and three passes are shown in Fig. 5 (a), (b) and (c) and respectively. The threepass image shows the agglomeration of the carbon material into graphite chunks on the surface with a visible dark area, shown in Fig. 5 (a). The two-pass shows less layers of graphite except at the end of the deposition where the nozzle spends more time as deposition finishes and a thick carbon is seen in Fig. 5 (b), while less number of layers is observed right before the nozzle is switched off.
For the three pass image of Fig. 5 (d), the graphene is seen to have covered the entire surface and the bright edges of the aluminum sheet is now more matte. The surface details of the aluminum substrate are still visible. The high energy nature of the process shows the turbostratic nature of the deposition as the graphene layers appear to have surface protrusions even after sonication.

Since the size of the graphene material is in micro-scale, an optical microscope (250X maximum magnification) was used to examine deposition patterns. It is visibly clear that more passes result in the reduction of number of layers seen as a lighter shade of gray in the successive images of Fig. 6 (c), (b) and (a).

Another interesting characterization technique was glow-discharge optical emission spectroscopy (GDOES), which works by ablating the surface of a sample via a plasma. The emissions from the material are analyzed and collected a spectrometer since specific elements emit radiation at specific signature wavelengths. Figure 7 shows the results for three and two passes against an aluminum reference at $3000 \mathrm{~Hz}$ asynchronous pulse frequency and $35 \mathrm{~W}$ power. Interestingly, specimens with graphene exhibited double peaks with successively less intensity, relating to the number of graphene layers available (less layers with more passes). 
Fig. 5 Field emission scanning electron microscopy (FE-SEM) images of $\mathbf{a}$ one pass, $\mathbf{b}$ two passes and $\mathbf{c}$ three passes of graphite blasting

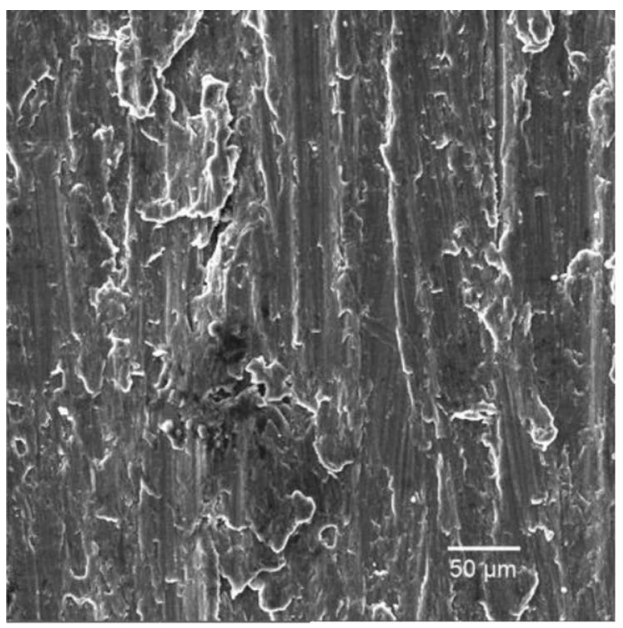

(a)

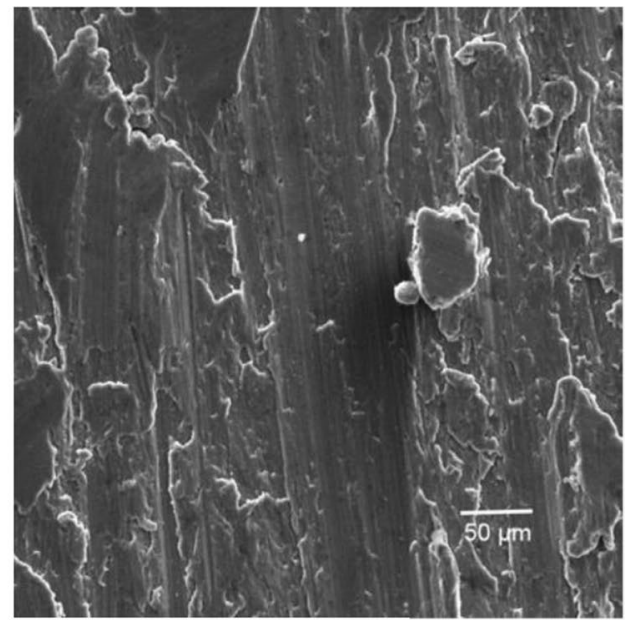

(b)

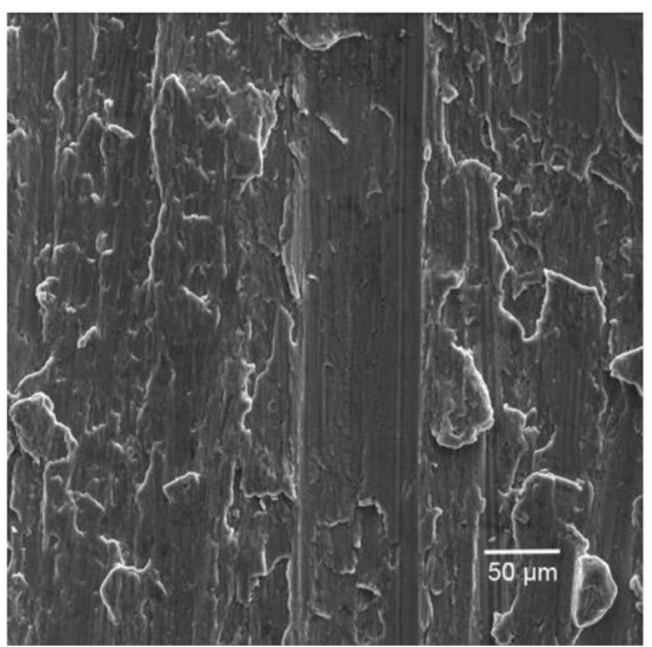

(c)

The strongly bonded carbon in the form of graphene at the surface of the specimens requires higher energy to dissociate than the aluminum substrate. The slow, yet steady rise of the aluminum signal indicates the sealing effect of the graphene nanoplatelets at the surface, allowing the aluminum to be detected at later stages of the analysis. And although the slopes of aluminum signal appear to have quite similar trends, they also show limited resistance to the generated plasma compared with the much larger area under the carbon signal in both 2 and 3 pass instances. Similar results have been reported by Takahara et al. [1], although in Fig. 7, the surface carbon peaks are more pronounced. These peaks are also split into two, mainly due to the existence of a large number of nanoplatelets in the plasma path in overlapping layers, which could also corroborate the existence of two graphene layers.

\subsection{Spectral properties}

In terms of spectral performance, the reflectivity data were subtracted from a whole to provide the results for absorbance, as a percentage. According to Beer-Lambert's Law, it was possible to transform the percentage reflectance into absorbance in absorbance unit (a.u.) by using the following equation:

$A=\log _{10}(1 / R)$

Shown in Fig. 8 (b), relative to the wavelength, the absorbance for all samples increases in the visible range and is then seen to decreases almost linearly for $\mathrm{S}_{2}$.

When compared to $S_{1}$, the spectra for the $S_{3}$ specimen increased three-fold Turbostratic graphene platelets appear to behave as gratings on the aluminum substrate which has notably improved the absorption process [20] as 

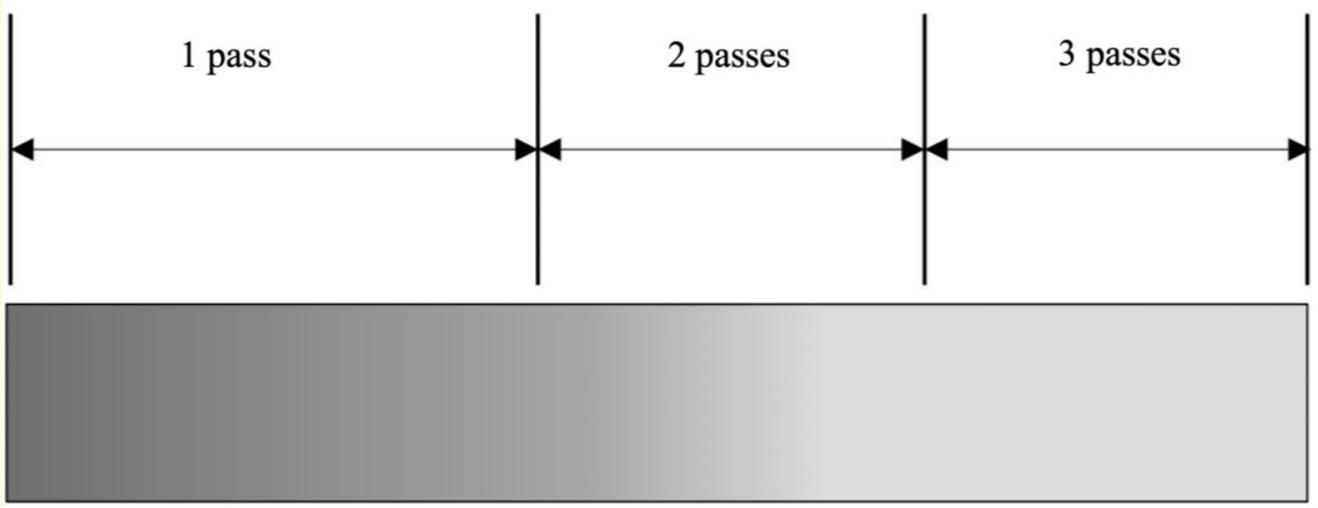

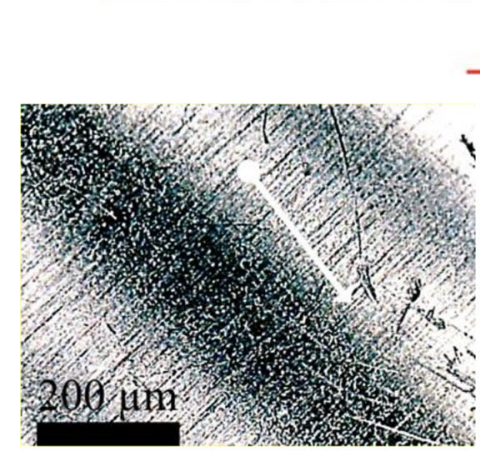

(a)

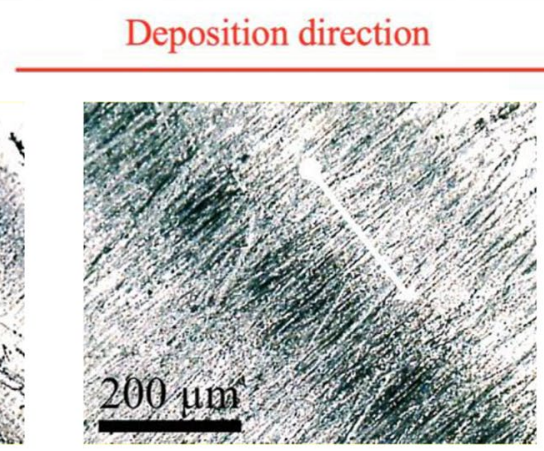

(b)

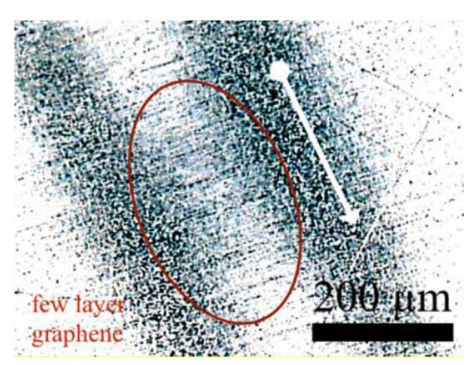

(c)

Fig. 6 Optical microscope images showing deposition direction (white arrow) of a one, $\mathbf{b}$ two and $\mathbf{c}$ three nozzle passes

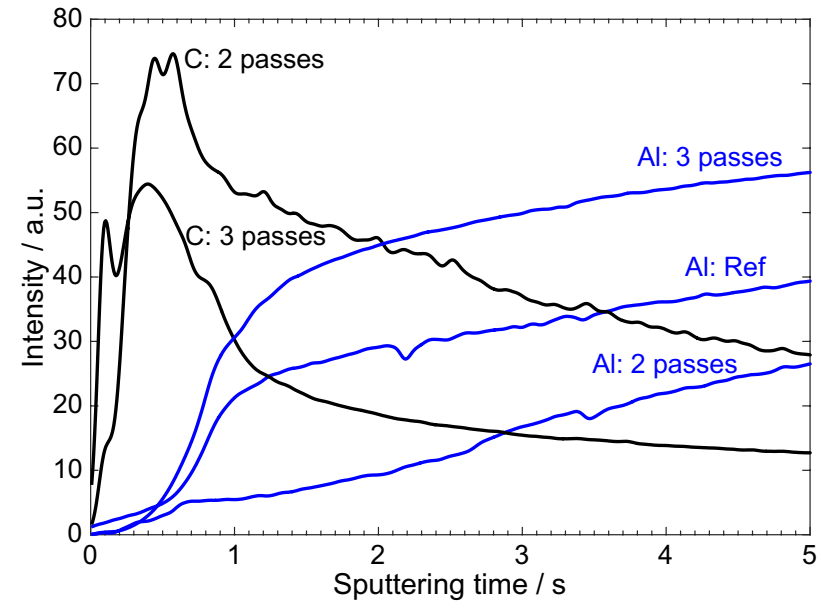

Fig. 7 glow discharge optical emission for an aluminum reference and two and three pass samples

the roughness of the substrate allows for multiple reflectance instances that lead back onto the substrate and thus results in an increased amount of absorbed irradiation by the turbostratic graphene at visible wavelengths.

The three samples were then thermally assessed on a heating plate against a reference aluminium specimen. The results of their thermal stability are shown in Fig. 9.
The distinct periodic fluctuation in the temperature profile is due to the heating plate thermostat.

The correlation of thermal behavior to number of blasting passes is an inverse one as the thermal properties of specimens undergoing 3 passes acquired enhanced thermal properties that is consistently $5 \%$ higher throughout the temperature ranges shown. This pattern is seen across all cycles and is extremely reproducible for the five repetitions that the thermal test was conducted. The graphene layer was still there after the test was done and has not hindered heat transfer from the surface of the specimens.

Thermal stability as well as corrosion resistance are important considerations for potential commercialization. Hence, the turbostratic graphene coverage has also been tested for its potential role in enhancing substrate corrosion resistance compared to the reference aluminum sample. The Tafel plot in Fig. 10 portrays this information where a 3-sigma chart showing the corrosion rate $\left(v_{\text {corr }}\right)$ for each sample is constructed using Eq. (4):

$v_{\text {corr }}=3.27 \times j_{\text {corr }} \times \frac{e}{\rho A}$

where $e$ is the equivalent weight of aluminum $(9 \mathrm{~g}), \rho$ is its density $\left(2.70 \mathrm{~g} \mathrm{~cm}^{-3}\right), A$ is the sample area $\left(0.25 \mathrm{~cm}^{2}\right)$ and $j_{\text {corr }}$ the corrosion current measured in $\mathrm{mA} / \mathrm{cm}^{2}$. It can 
Fig. 8 a UV and b visible absorbance spectra of the single (S1), second pass (S2), and third pass (S3) samples from the various wavelengths of the electromagnetic spectrum

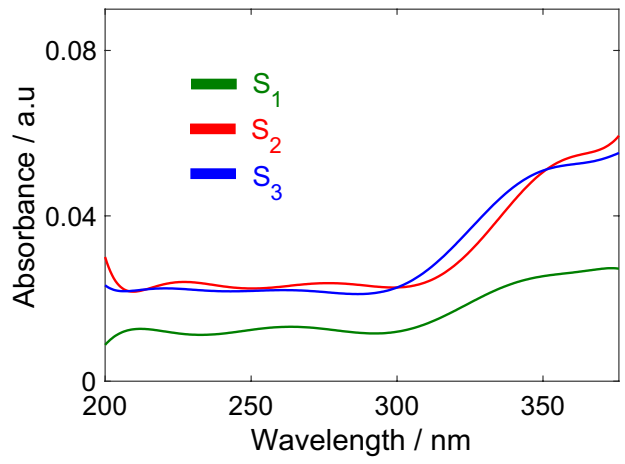

(a)

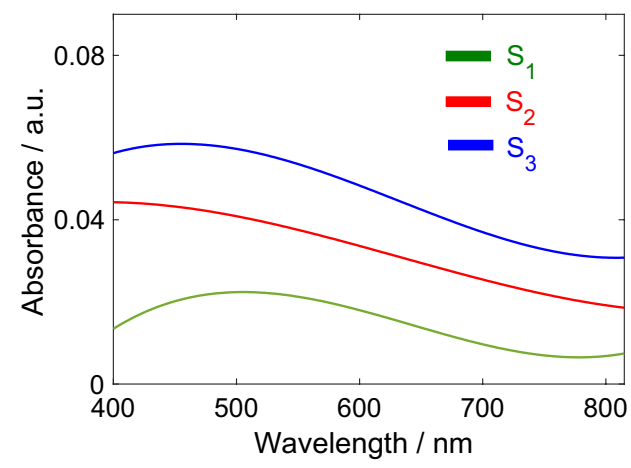

(b)

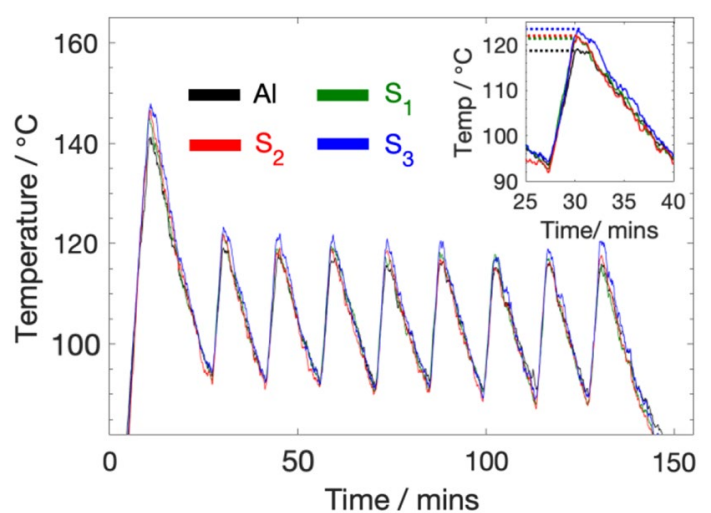

Fig. 9 Temperature profile of the single (S1), second pass (S2), and third pass (S3) samples

be seen from the equation that the corrosion rate $\left(v_{\text {corr }}\right)$ strongly correlates to the corrosion current $j_{\text {corr }}$.

The polarization curves of the corrosion of aluminum covered with turbostratic graphene against a bare aluminum reference is depicted in Figure (a). In the turbostratic graphene-coated aluminum substrates, it can be seen that the Tafel region produced by the anodic curves is long and distinct in comparison to that of the bare aluminum. It can also be seen that the substrates covered with turbostratic graphene produced increased potentials in comparison to the potentials produced by the bare aluminum this was demonstrated through the polarization curves. This indicates the requirement for higher amounts of energy needed to trigger the electrochemical reaction.

Correlating results within the graphene-coated substrates, it can be seen that applying a single pass of graphite to the substrate surface, as is the case with $\mathrm{S}_{1}$, causes an enhancement of the corrosion. This is akin to how pitting corrosion starts and propagates. There exist small spaces that has no turbostratic graphene coverage and these will create more concentrated corrosion attacks and hence register higher material loss, as seen in Figure (b). The 3-pass specimen $\left(\mathrm{S}_{3}\right)$, on the other hand, achieved better homogeneity and is therefore seen to exhibit the lowest corrosion rate value of $0.005 \mathrm{mmpy}$.

Graphene is hydrophobic in nature and it would prevent hydrogen bonding with water [21]. This would result in better resistance to pitting corrosion reactions. Also, the slope of a tangent to the bare, 1-pass and 2-pass samples were found to be more compared to the 3-passes samples. It is an indication of the small initial density $\left(J_{0}\right)$ of the 3-pass specimen and of its ability to highly resist corrosion [22].
Fig. 10 a Tafel plot and $\mathbf{b}$ the corrosion rate test control limits for the single (S1), two pass (S2), and three pass (S3) specimens against bare aluminium

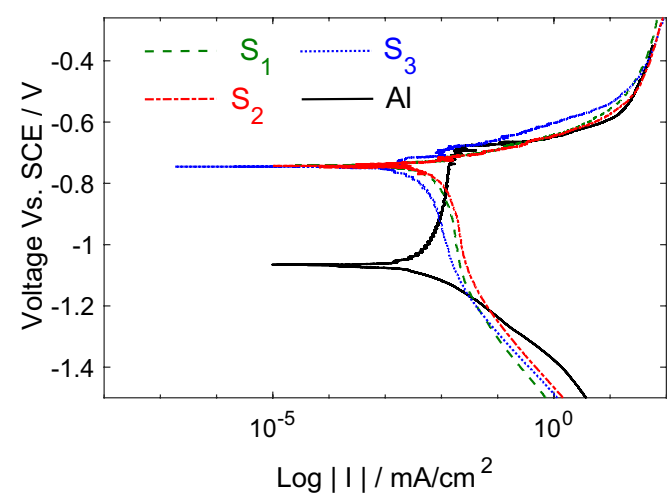

(a)

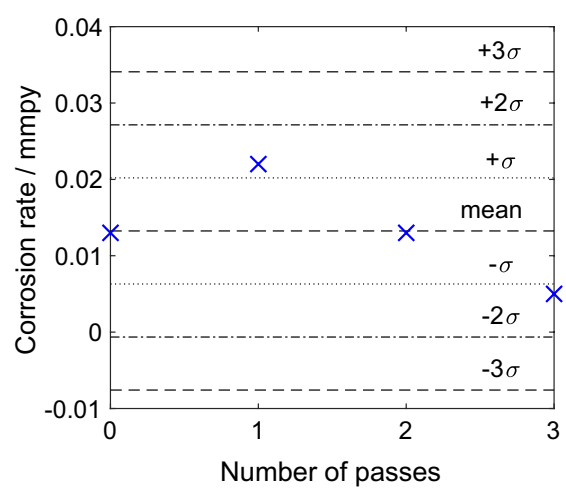

(b) 


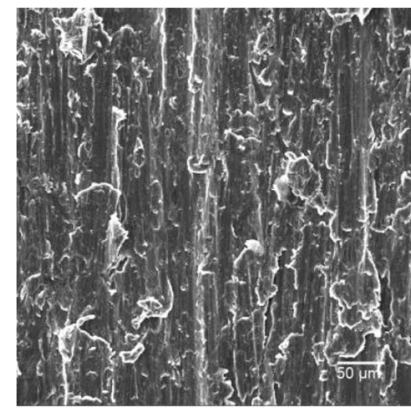

(a)

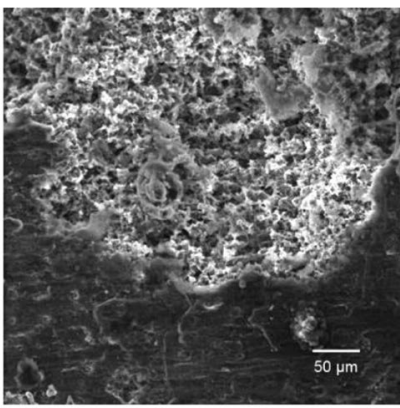

(b)
Fig. 11 SEM images of bare aluminum substrate $\mathbf{a}$ before and $\mathbf{b}$ after electrochemical testing

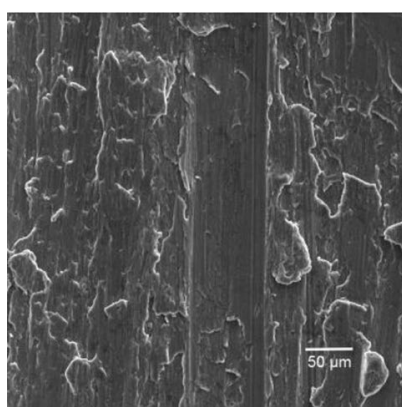

(a)

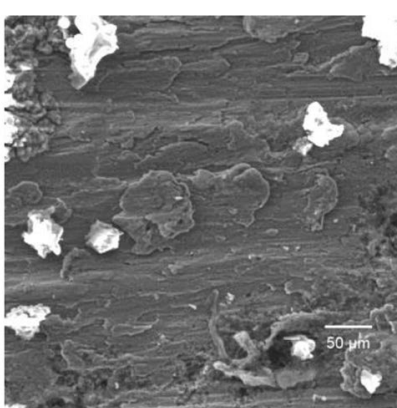

(b)
Fig. 12 SEM images of three-pass sample substrate (S3) a before and $\mathbf{b}$ after electrochemical testing

The plots shown in Figure portray the rates of corrosion for the samples covered by turbostratic graphene in comparison to basic aluminum. Figures 11 and 12 add a more visual appeal in the form of SEM images to the corrosion properties the added turbostratic graphene displays. SEM images of the samples undergoing turbostratic graphene deposition resulted in less surface destruction. Not shown here.

\section{Discussion}

The deposition system can be commercialized as a desktop deposition system, as depicted in Fig. 13 for various applications. It is advantageous to include a cost estimate to better appreciate the costs pertinent to the hardware and consumables required. The estimated cost can be divided into variable and fixed costs. The costs of

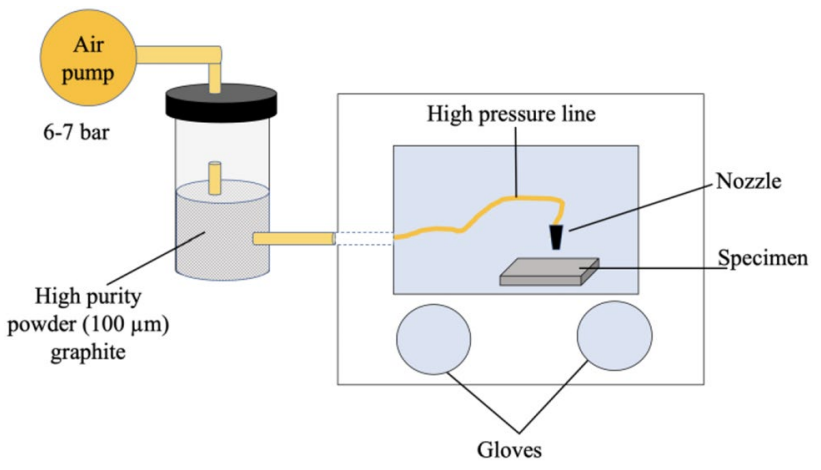

Fig. 13 Depiction of the deposition chamber

the setup and automation are considered as fixed costs whereas the variable costs include the materials.

The analysis was conducted per month for 8-h shifts per day and under the electrical consumption requirement in the United Arab Emirates of $<1 \mathrm{MW}$ for a cost value of $0.078 \$ \mathrm{k}^{-1} \mathrm{Wh}$.

The following tables detail the estimated cost analysis for the graphene deposition system for a solar thermal absorber application in relation with that obtained commercially. The plates consisting of both aluminum fins as well as copper tubing with a maximum active area of 1 by $4 \mathrm{~m}$ absorber is being sold on the market for $\$ 344-402$ by Sun Ray Solar. The cost of labor (Table 1), cost of one-time deposition system construction (Table 2), fixed costs for operation, electrical consumption are shown in Tables 3, 4 and 5, and finally the total cost is shown in Tables 6 and 7. It is estimated, based on the results obtained from the solar cell collector construction and testing that the graphene-coated absorber efficiency reaches sound values of around $94.6 \%$ that opportunely surpasses those sold commercially by Sun Ray Solar with an efficiency of $94 \%$. It is important to note that while the difference in efficiencies is small, commercial absorbers would have undergne intesive improvement procedures such as professional metal finishing and anti-reflective coatings etc. This would optimize their efficiency for comparison, whereas the graphenecoated absorbers in this study have room for further improvement even with the increased efficiency they have attained. The straightforawrd process is therefore suggested to be used as a coating on existing solar absorbers for as an efficiency-enhacing layer. 
Table 1 Distribution of the fixed cost for human resources

\begin{tabular}{|c|c|c|c|c|c|}
\hline $\begin{array}{l}\text { Fixed cost for } 8 \mathrm{~h} \\
\text { shifts at } 6 \text { sub- } \\
\text { strates per day }\end{array}$ & Unit cost (\$) & Quantity & Total cost (\$) & Rate & References \\
\hline \multicolumn{6}{|l|}{ Human } \\
\hline Labour & $\$ 435.20$ & 1 & $\$ 435.20$ & Per month & - \\
\hline Machinist & $\$ 1089.60$ & 1 & $\$ 1089.60$ & Per month & - \\
\hline \multicolumn{6}{|l|}{ Health and safety } \\
\hline $\begin{array}{l}\text { Personal Protec- } \\
\text { tive Equipment } \\
\text { (Suit \& Helmet) }\end{array}$ & $\$ 1090.00$ & 1 & $\$ 1090.00$ & - & $\begin{array}{l}\text { Qingdao Jichuan } \\
\text { Machinery Manufac- } \\
\text { turing Co }\end{array}$ \\
\hline
\end{tabular}

Table 2 Distribution of the fixed cost for construction

\begin{tabular}{|c|c|c|c|c|c|}
\hline $\begin{array}{l}\text { Fixed cost for } 8 \mathrm{~h} \text { shifts at } 6 \text { substrates per } \\
\text { day }\end{array}$ & Unit cost (\$) & Quantity & Total cost (\$) & Rate & References \\
\hline \multicolumn{6}{|l|}{ Construction } \\
\hline \multicolumn{6}{|l|}{ (1) Framework } \\
\hline \multicolumn{6}{|l|}{ (a) Body } \\
\hline $\begin{array}{l}\text { Sandblasting Room Body } \\
(5 \mathrm{~m} \times 3.5 \mathrm{~m} \times 2.6 \mathrm{~m}(\mathrm{H}))\end{array}$ & $\$ 2030.00$ & 1 & $\$ 2030.00$ & - & $\begin{array}{l}\text { Qingdao Jichuan Machinery Manufac- } \\
\text { turing Co }\end{array}$ \\
\hline Automated sample compartment holder & $\$ 1000.00$ & 1 & $\$ 1000.00$ & - & $\begin{array}{l}\text { Qingdao Jichuan Machinery Manufac- } \\
\text { turing Co }\end{array}$ \\
\hline Ventilation system & $\$ 26.58$ & 1 & $\$ 26.58$ & - & Alibaba.com \\
\hline Lighting System (70 W*8pc LED Lamp) & $\$ 39.00$ & 8 & $\$ 312.00$ & - & $\begin{array}{l}\text { Qingdao Jichuan Machinery Manufac- } \\
\text { turing Co }\end{array}$ \\
\hline \multicolumn{6}{|l|}{ (b) Sample holder } \\
\hline Plastic sheet & $\$ 29.20$ & 2 & $\$ 58.40$ & Per month & Grainger.com \\
\hline Magnetic framework & $\$ 1.55$ & 476 & $\$ 737.80$ & - & Grainger.com \\
\hline \multicolumn{6}{|l|}{ (2) Storage unit } \\
\hline Storage rack & $\$ 71.00$ & 1 & $\$ 71.00$ & - & Grainger.com \\
\hline
\end{tabular}

Table 3 Distribution of the fixed cost for experimental operation

\begin{tabular}{|c|c|c|c|c|c|}
\hline Fixed cost for $8 \mathrm{~h}$ shifts at 6 substrates per day & Unit Cost (\$) & Quantity & Total cost $(\$)$ & Rate & References \\
\hline \multicolumn{6}{|l|}{ Operation } \\
\hline \multicolumn{6}{|l|}{ (1) Graphene deposition } \\
\hline Sand blasting pot \& Accessories (Model: Q250-I-JX) & $\$ 1975.00$ & 1 & $\$ 1975.00$ & - & $\begin{array}{l}\text { Qingdao } \\
\text { Jichuan } \\
\text { Machinery } \\
\text { Manufactur- } \\
\text { ing Co }\end{array}$ \\
\hline Air compressor & $\$ 3040.00$ & 1 & $\$ 3040.00$ & - & $\begin{array}{l}\text { Qingdao } \\
\text { Jichuan } \\
\text { Machinery } \\
\text { Manufactur- } \\
\text { ing Co }\end{array}$ \\
\hline \multicolumn{6}{|l|}{ (2) Automation } \\
\hline $80 / 20$ framing system & $\$ 370.00$ & - & $\$ 370.00$ & & Joescnc.com \\
\hline Carriage plates (Aluminum) & $\$ 565.00$ & - & $\$ 565.00$ & & Joescnc.com \\
\hline Motor drives and gear racks & $\$ 480.00$ & - & $\$ 480.00$ & & Joescnc.com \\
\hline
\end{tabular}


Table 4 Distribution of the fixed cost for equipment electrical consumption

\begin{tabular}{|c|c|c|c|c|c|}
\hline Fixed cost for $8 \mathrm{~h}$ shifts at 6 substrates per day & Unit cost (\$) & Quantity & Total cost (\$) & Rate & References \\
\hline \multicolumn{6}{|l|}{ Electrical } \\
\hline Electricity & $\$ 86.61$ & - & $\$ 86.61$ & Per month & - \\
\hline $\begin{array}{l}\text { Power supply controllers, PLC control and electronic sen- } \\
\text { sors + Electronic kit-power supply-controllers-wiring- } \\
\text { motors }\end{array}$ & $\$ 2600.00$ & - & $\$ 2600.00$ & - & Joescnc.com \\
\hline Desktop computer & $\$ 300.00$ & - & $\$ 300.00$ & - & - \\
\hline
\end{tabular}

Table 5 Price of electrical consumption per kWh in the UAE at $0.078 \$ / \mathrm{kWh}$ with a breakdown of the equipment used in the deposition process under the limit of $1 \mathrm{MW}$

\begin{tabular}{ll}
\hline Equipment & $\begin{array}{l}\text { Power } \\
\text { consumption } \\
(\mathrm{kWh})\end{array}$ \\
\hline Compressor & 2.2 \\
Motor-CNC & 0.9 \\
Computer & 0.2 \\
Blasting mechanism & 3.5 \\
Motor-exhaust fan & 0.07 \\
Light (LED) & 0.07 \\
\hline
\end{tabular}

\section{Conclusions}

Applications with turbostratic graphene have proven to enhance the performance of various devices that rely on surface condition and thus benefit from surface modification. There is a need and demand to apply graphene on surfaces at a large scale where chemical processes will not suffice in terms of process speed and product quality. Mechanical exfoliation is a form of turbostratic graphene synthesis but typically, the yield is generally quite low. This study presents an adaptable process to synthesize and deposit turbostratic graphene. The system consists of a motion controlled blasting system that discharges graphite powder onto a metallic substrate where it undergoes shear forces and yields graphene of disordered structure.

Raman characterization of the deposited coating shows homogeneous coverage with exceptional electrochemical properties exceeded by the sample undergoing three passes. The homogeneity in the coating allowed for better spectral performances aiding in the overall absorbance of the aluminum substrate. Since graphite is in powder form and is quite dangerous to be allowed to remain suspended in air, an enclosure where automation for the coating process is accomplished. The process that results in large-scale coated substrates can then be used for various applications that requires homogenous coating of graphene. As a future plan, in-situ and ex-situ analysis of the evolution of the graphene turbostratic layers can be done via TEM or SEM.

A cost analysis of the proposed system indicates that it can be built and operated with a price tag of less than $\$ 18,000$, resulting in active components (e.g. solar absorbers) that are around $40 \%$ less costly than commercially available components delivering the same efficiency.
Table 6 Distribution of the variable cost materials

\begin{tabular}{llllll}
\hline Variable cost per month & Unit cost & Quantity & Total cost $(\$)$ & Rate & Reference \\
\hline $\begin{array}{l}\text { (1) Materials } \\
\text { Graphite Powder }\end{array}$ & - & $540 \mathrm{~kg}$ & $\$ 100.00$ & per month & Alibaba.com \\
$\begin{array}{l}\text { Black—coated aluminum } \\
\text { sheets }(2 \times 2 \text { m per sub- }\end{array}$ & $\$ 4.3 / \mathrm{m}^{2}$ & $240 \mathrm{~m}^{2}$ & $\$ 1,032.00$ & per month & BTE Solar \\
strate) & & & & & \\
\hline
\end{tabular}

Table 7 Breakdown of the total cost per unit and a comparison of a commercial absorber

\begin{tabular}{|c|c|c|c|c|}
\hline Total fixed cost (\$) & Total variable cost (\$) & $\begin{array}{l}\text { Total Cost }=\text { Fixed Cost }+ \text { Vari }- \\
\text { able Cost }\end{array}$ & $\begin{array}{l}\text { Total cost per unit }=(\text { Fixed } \\
\text { Cost }+ \text { Variable Cost }) / \text { Units } \\
\text { produced }\end{array}$ & $\begin{array}{l}\text { Price of commercial absorber } \\
\text { with similar area }\end{array}$ \\
\hline$\$ 16,442.09$ & $\$ 1132.00$ & $\$ 17,399.19$ & $\begin{array}{l}\text { \$144.99 at } 94.6 \% \text { absorber } \\
\text { efficiency }\end{array}$ & $\begin{array}{l}\$ 225-284 \text { at } 94 \% \text { absorber } \\
\text { efficiency Sun Ray Solar }\end{array}$ \\
\hline
\end{tabular}


Authors Contributions Kamilia Aokal: data curation, analysis, original manuscript writing and editing. Abdul Hai Alami: conceptualization, writing and editing and supervision. Ali Cheaitou: writing and editing. Mohammad Ali Abdelkareem: writing and editing.

Data availability The authors confirm that they have generated and have access to all reported data.

\section{Declarations}

Competing interests The authors have no relevant financial or nonfinancial conflicting interests to disclose.

Ethical approval The authors confirm that there are no ethical issues associated with this manuscript.

Consent to participate The authors give their permission to publish this work in JAMT.

Consent to publish The authors give their permission to publish this work in JAMT.

Open Access This article is licensed under a Creative Commons Attribution 4.0 International License, which permits use, sharing, adaptation, distribution and reproduction in any medium or format, as long as you give appropriate credit to the original author(s) and the source, provide a link to the Creative Commons licence, and indicate if changes were made. The images or other third party material in this article are included in the article's Creative Commons licence, unless indicated otherwise in a credit line to the material. If material is not included in the article's Creative Commons licence and your intended use is not permitted by statutory regulation or exceeds the permitted use, you will need to obtain permission directly from the copyright holder. To view a copy of this licence, visit http://creativecommons. org/licenses/by/4.0/.

\section{References}

1. Alami AH, Aokal K (2018) Enhancement of spectral absorption of solar thermal collectors by bulk graphene addition via highpressure graphite blasting. Energy Convers Manag 156:757-764

2. Alami AH, Hawili AA, Chaker N (2018) Experiments on surface hardening of aluminum components by high-energy centrifugal milling. Int J Adv Manuf Technol 95(9-12):3855-3862

3. Pierson HO (1993) Handbook of Carbon. Graphite, Diamond and Fullerenes

4. Kim K, He J, Ganeshan B, Liu J (2018) Disorder enhanced thermal conductivity anisotropy in two-dimensional materials and van der Waals heterostructures. J Appl Phys 124(5):055104

5. Cao $Y$ et al (2018) Unconventional superconductivity in magicangle graphene superlattices. Nature 556(7699):43-50
6. Cao Y et al (2018) Correlated insulator behaviour at half-filling in magic-angle graphene superlattices. Nature 556(7699):80-84

7. He J, Kim K, Wang Y, Liu J (2018) Strain effects on the anisotropic thermal transport in crystalline polyethylene. Appl Phys Lett 112(5):051907

8. Zhu T, Ertekin E (2014) Phonon transport on two-dimensional graphene/boron nitride superlattices. Phys. Rev. B - Condens. Matter Mater. Phys. 90(19):195209

9. Tian X, Itkis ME, Bekyarova EB, Haddon RC (2013) Anisotropic thermal and electrical properties of thin thermal interface layers of graphite nanoplatelet-based composites. Sci Rep 3(1):1-6

10. Ferrari $A C$ et al (2015) Science and technology roadmap for graphene, related two-dimensional crystals, and hybrid systems. Nanoscale 7(11):4598-4810

11. Mizuno H, Mossa S, Barrat JL (2015) Beating the amorphous limit in thermal conductivity by superlattices design. Sci Rep 5(1):1-15

12. Luican A et al (2011) Single-layer behavior and its breakdown in twisted graphene layers. Phys Rev Lett 106(12):126802

13. Hass $\mathrm{J}$ et al (2008) Why multilayer graphene on $4 \mathrm{H}-\mathrm{SiC}(000 \mathrm{~T})$ behaves like a single sheet of graphene. Phys Rev Lett 100(12):125504

14. A. K. Gupta, Y. Tang, V. H. Crespi, and P. C. Eklund, "Nondispersive Raman $\mathrm{D}$ band activated by well-ordered interlayer interactions in rotationally stacked bilayer graphene," Phys. Rev. B - Condens. Matter Mater. Phys., vol. 82, no. 24, p. 241406, Dec. 2010.

15. Novoselov KS et al (2005) Two-dimensional atomic crystals. Proc Natl Acad Sci U S A 102(30):10451-10453

16. Alami AH, Aokal K, Assad MA, Zhang D, Alawadhi H, Rajab B (2017) One-step synthesis and deposition of few-layer graphene via facile, dry ball-free milling. MRS Advances 2(15):847-856

17. Alami AH, Aokal K, Zhang D, Soudan B (2018) Bulk turbostratic graphene deposition on aluminum substrates via high-pressure graphite blasting. Appl Nanosci 8(8):1943-1950

18. Alami AH, Assad MA, Aokal C (2016) Facile and cost-effective synthesis and deposition of a YBCO superconductor on copper substrates by high-energy ball milling. Metall Mater Trans A 47(12):6160-6168

19. Ferrari AC et al (2006) Raman spectrum of graphene and graphene layers. Phys Rev Lett 97(18):187401

20. Zhao B, Zhao JM, Zhang ZM (2014) Enhancement of near-infrared absorption in graphene with metal gratings. Appl Phys Lett 105(3):031905

21. Chen Z, Ren W, Gao L, Liu B, Pei S, Cheng HM (2011) Threedimensional flexible and conductive interconnected graphene networks grown by chemical vapour deposition. Nat Mater 10(6):424-428

22. Bunch JS et al (2008) Impermeable atomic membranes from graphene sheets. Nano Lett 8(8):2458-2462

Publisher's Note Springer Nature remains neutral with regard to jurisdictional claims in published maps and institutional affiliations. 